\section{Transfer of information-seeking strategy in preschool children}

\author{
NORMA L. LI and NANCY I). TAYLOR* \\ Sir George Williams University, Montreal, P.Q., Canada
}

Five-year-olds were asked to identify in as few presses as possible which of two patterns was present on a bulb board. Children placed under constraint on the first problem by being permitted only one press at a time but left free when solving a second immediately afterward solved both problems more quickly than Ss who never experienced constraint. Experiment 2 showed that asking children whether they know the answer after each response improves performance by affecting attention, but being permitted only one press at a time accounts for efficient use of information under constraint and transfer 2 days later.
Olson (1966) investigated information-seeking strategies in children by asking them to find in as few presses as possible which of two patterns was preset on an electric bulb board. He found that when permitted only one press at a time, $20 \%$ of the 5 -year-olds and $80 \%$ of the 7 - and 9 -year-olds tested adopted a highly tendency to press on-pattern bulbs and a high frequency of solutions following the first informative press. children either.systematically searched the board without reference to the models or successively traced the patterns. Olson suggested that constraint was effective because it forced the child to use symbolic rather than iconic representation and implied that when constraint was removed the child would revert to his customary less effective strategies. He failed to consider that the major function of constraint might be to teach the child how to attack the problem and something about the nature of the information necessary to solve it. Experiment 1 investigated this possibility by examining the performance of 5-year-olds using a transfer paradigm.

\section{EXPERIMENT 1}

\section{Subjects}

The $\mathrm{Ss}$ were 28 middle-class children, 60 to 64 months old, from three suburban nursery schools. The mean age of the sample was 62 months.

\section{Apparatus}

The bulb board was a gray metal box with $91 / 2$-in.-diam bulbs mounted $1 / 2$ in. apart in a 3 by 3 matrix. Each bulb was controlled by a separate

*The authors wish to express their appreciation to the staff and children of Laval Jewish Community Centre y Nursery School, Mount Royal Nursery School, Nurserv, and Sunnybrook Co-Operative Preschool for their cooperation in carrying out the experiments. efficient strategy characterized by a Without such : external constraint, Mount Royal United Church Observation manual switch on the back of the box. When preset, bulbs lit up to a bright red when pressed but went off when released. When off, bulbs appeared dark red.

The models constituting each problem were fastened to a $12 \times 12 \mathrm{in}$. blackboard placed upright behind the bulb display. Each was constructed by making a 3 by 3 matrix of circular stickers on a $3 \frac{1 / 2-i n}{}$. square of gray construction paper. Bright red stickers were used to represent on-pattern bulbs and dark red ones to represent off-pattern bulbs.

\section{Problems}

The pretest and experimental problems are shown in Fig. 1, in which $\mathrm{Xs}$ represent on-pattern bulbs. Each prot!@m involved a choice between two models; the one shown on the left of each diagram was the correct answer.

\section{Procedure}

Each $\mathrm{S}$ was tested individually in two sessions 1 week apart. In the first session, the child was introduced to the task and given a pretest. After being seated at the table on which the apparatus had been placed, he was first shown how the bulbs could light up to correspond to a design which the $\mathrm{E}$ could preset prior to presenting a problem. He was ther shown the models for the pretest problem and asked to find in as few presses as possible which "picture" had been hidden on the bulb board. He was told that he could press as many bulbs, one at a time, as was necessary to find the answer and that as soon as he knew it, he was to point to the correct model. Instructions were repeated only if the child seemed to be faltering. A 2 -min time limit was used. The score was the number of presses to solution.

Pretest scores were used to create two matched groups of 14 Ss for the second session, when each child was required to solve two more difficult problems. Each $\mathrm{S}$ in the experimental group solved the first problem under constraint. He was told to find which "picture" was "hidden" by taking one press and that, since he had only one press, he was to think very carefully. After a single press, he was asked whether he knew the answer at that point. If he did not know, he was asked if he would like another press to make sure, the instructions were repeated, and, following his response, he was again asked if he knew the answer. This procedure continued until he gave the correct answer. He was then given the second problem to solve without constraint. The procedure was the same as for the pretest. Control Ss solved both problems without constraint. A 3-min time limit was used for each problem.

To control for possible differences in difficulty, the order in which the experimental problems were presented was counterbalanced within each group. The correct model was placed on the left side of the display for the problem presented first and on the right for the problem presented second.
$x \times x$
(1) 00
1) 00
and
$00 x$
o $0 x$
$00 x$

Pretest

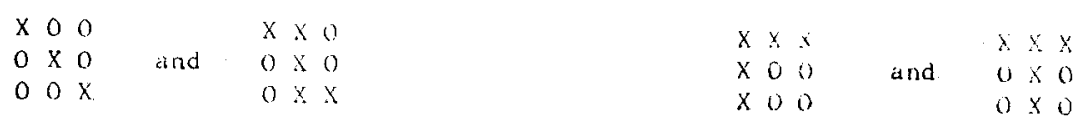


Table 1

Medians and Quartile Deviations for Number of Presses to Solution for Each Group on Each Problem

\begin{tabular}{|c|c|c|c|c|c|c|}
\hline \multirow[b]{2}{*}{ Group } & \multicolumn{2}{|c|}{ Pretest } & \multicolumn{2}{|c|}{ Training } & \multicolumn{2}{|c|}{ Transfer } \\
\hline & Median & QD & Median & $\mathrm{QD}$ & Median & QD \\
\hline Constraint & 5.83 & 3.00 & 3.50 & 1.50 & $\mathbf{5 . 5 0}$ & $\mathbf{3 . 5 0}$ \\
\hline Control & 5.50 & 3.00 & 8.00 & 3.50 & 10.00 & 3.50 \\
\hline
\end{tabular}

\section{Results}

Table 1 shows the median number of presses to solution for both groups on each problem. Ss under constraint on the first experimental problem achieved solution in fewer presses than did controls (Mann-Whitney large-sample procedure: $\mathrm{z}=3.86$, $\mathrm{p}<.01)$; in 11 cases, in contrast to 1 control, solution followed the first informative press $\left(\chi^{2}=11.81, \mathrm{df}=1\right.$, $\mathrm{p}<.001)$. On the second problem, Ss who had experienced constraint on the first still achieved solution more quickly than did controls (Mann-Whitney: $z=2.46, p<.05$ ), but produced only five solutions after the first informative press. Since two such solutions occurred in the control group, the chi-square value was not significant. While the scores of both groups tended to be higher on the second of the two experimental problems, Wilcoxon tests showed that changed significantly from the first to the second problem.

\section{Discussion}

The performance of the childrer under constraint was distinguished by the same characteristics described by Olson, although he found such a high frequency of solutions after the first informative press typical of children only 7 years or older. Since the experimental Ss solved the second problem faster than did the controls, there was clear evidence of transfer attributable to the constraint procedure. The drop in the number of solutions following the first informative press indicated, however, that few children transferred the strategy elicited under constraint in its entirety. Since the transfer test followed the training problem immediately, the superior performance on it of the children who had previously experienced constraint might have reflected in part greater attention to the task, attributable to the admonition to think carefully before each press under constraint and the enquiry afterward as to whether the child knew the answer.

\section{EXPERIMENT 2}

Experiment 2 was designed to seen in Experiment 1 by isolating the effects of the principal components of the constraint procedure in a remote transfer paradigm. the performance of neither group clarify the nature of the transfer effect he was asked whether he knew the answer after the ninth and every subsequent fifth press until he achieved solution.

Treatment of the groups differed only on the training problem. One group solved under constraint, being told without emphasis before each press, "You may have one press," and being asked afterward, "Do you know the answer now?" The procedure differed from that used in Experiment 1 only in the omission of the statement about thinking carefully because only one press was permitted. This change was made in order to isolate the effect of the salient characteristic of the constraint procedure: being permitted only one press at a time. A second group was used to investigate the possible effect on attention of the question following each press, which is an integral part of the constraint procedure. Ss in the attention control group solved the training problem under the same preliminary instructions as on the pretest but were asked after each press, "Do you know the answer now?" and were told, "Go on," if they did not. The third group was included specifically to investigate the effect of questions following informative presses. The procedure for the information control group differed from that for the attention control group only in that these Ss were asked whether they knew the answer only after each informative press on the training problem. A Latin square, repeated for each group, was used to assign the experimental problems $(P$, $Q, \quad R)$ to the training, immediate transfer, and remote transfer conditions.

\section{Results}

Table 2 shows the median number of presses to solution for each group on each problem. The data were analyzed using Wilcoxon tests for within-group comparisons and the Mann-Whitney procedure for large model as soon as he knew the answer. If he did not solve the problem earlier,

\begin{tabular}{|c|c|c|}
\hline $00 x$ & & \\
\hline $00 x$ & and & \\
\hline$x \times x$ & & \\
\hline
\end{tabular}

Pretest

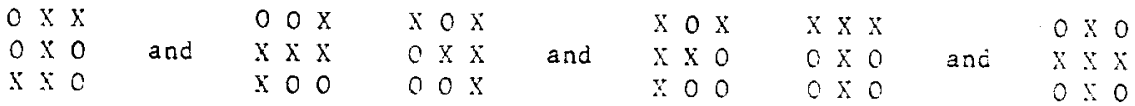


samples tor between-group comparisons. The adequacy of the matching was confirmed by the fact that there were no significant differences between groups on the pretest. On the training problem. Ss in the information control group were asked whether they knew the answer significantly less often than were those in the attention control group; the medians were 2.50 and 4.83 , respectively $(\mathrm{z}=2.95, \mathrm{p}<.01)$. The two control groups did not differ, however, on the number of presses to solution on the training or transfer problems. All groups improved from the pretest to the training problem, with the effect being most marked in the Ss experiencing constraint (constraint: $\mathrm{T}=0, \mathrm{~N}^{\prime}=11, \mathrm{p}<.01$; attention: $\mathrm{T}=9.0, \mathrm{~N}^{\prime}=11, \mathrm{p}<.05$; information: $\mathrm{T}=7.5, \mathrm{~N}^{\prime}=11$, $\mathrm{p}<.05)$. Both control groups showed a significant deterioration in performance from the training problem to the $48 \mathrm{~h}$ (attention: $\mathrm{T}=2.0, \mathrm{~N}^{\prime}=11, \mathrm{p}<.01:$ information: $\mathrm{T}=6.0, \mathrm{~N}^{\prime}=11, \mathrm{p}$ $<.02$ ), but not the immediate transfer test, although performance on the immediate as well as the $48 \cdot \mathrm{h}$ transfer problem did not differ significantly from the pretest level in either group. Children in the constraint group took longer to solve the immediate transfer than the training problem $\left(\mathrm{T}=5, \mathrm{~N}^{\prime}=10\right.$, $\mathrm{p}<.02)$; nevertheless, their performance on the test for immediate transfer was superior to the pretest level $\left(\mathrm{T}=13.5, \mathrm{~N}^{\prime}=12, \mathrm{p}<.05\right)$. The data obtained for this group on the 48 h transfer test, unlike that for the immediate transfer test, was clearly dichotomous: half the Ss achieved solution in from 1 to 4 presses and the rest in from 8 to 19 . This dichotomy was reflected in the results of the statistical tests, which indicated that the performance of the group 2 days after training no longer differed significantly from either the pretest or the training level.

On the training problem, Ss in the constraint group achieved solution in fewer presses than did the attention controls $(z=2.59, p<.01)$ but showed only a marginal superiority to the information controls $(\mathrm{z}=1.76$, $p<.10$, two-tailed test). Although the children who had experienced constraint did not differ significantly from control Ss in either group in the number of presses required to solve the immediate transfer problem, they did demonstrate a marginal superiority to Ss in both control groups on the 48 - h transfer test (attention: $z=1.67$, $\mathrm{p}<.10$, two-tailed test; information: $z$ $=1.73, \mathrm{p}<.10$, two-tailed test .

In addition, 11 Ss under constraint achieved solution of the training problem after the first informative

Table 2

Medians and Quartile Deviations for Number of Presses to Solution for Each Group on Each Problem

\begin{tabular}{|c|c|c|c|c|c|c|c|c|}
\hline \multirow[b]{2}{*}{ Group } & \multicolumn{2}{|c|}{ Pretest } & \multicolumn{2}{|c|}{ Training } & \multicolumn{2}{|c|}{$\begin{array}{c}\text { Immediate } \\
\text { Transfer } \\
\end{array}$} & \multicolumn{2}{|c|}{$\begin{array}{c}48-\mathrm{H} \\
\text { Transfer }\end{array}$} \\
\hline & Median & $Q D$ & Median & $\mathrm{QD}$ & Median & $Q D$ & Median & $\mathrm{QD}$ \\
\hline Constraint & 9.25 & 3.00 & 2.25 & 1.20 & 6.50 & 3.33 & 6.00 & 3.50 \\
\hline Attention & 9.50 & .88 & 4.83 & 1.50 & 8.75 & 2.75 & 9.10 & 2.92 \\
\hline Information & 9.10 & 2.25 & 3.50 & 1.92 & 8.83 & 3.00 & 9.25 & 3.08 \\
\hline
\end{tabular}

press, in contrast to 2 Ss in the attention $\left(x^{2}=10.79, \mathrm{df}=1, \mathrm{p}<.01\right)$ and $4 \mathrm{Ss}$ in the information $\left(\mathrm{x}^{2}=\right.$ $6.39, \mathrm{df}=1, \mathrm{p}<.02)$ groups. The groups did not differ on this measure on the immediate transfer test, when the number of solutions following the first informative press dropped to three for Ss who had experienced constraint compared to one in each control group. On the $48 \cdot \mathrm{h}$ transfer test, however, four such solutions were produced by Ss who had experienced constraint, but none by control children (constraint vs combined control groups: $x^{2}=5.94, \mathrm{df}=1$, $p<.02$ ).

The control group data are consistent with the interpretation that the major function of the enquiry made of the child after each response under constraint is that it keeps his attention focused on solving the problem. Although information controls performed slightly better than did attention controls on the training problem, the results did not indicate any significant differences between the effects of the two control procedures. It seems unlikely that the marked improvement in performance of the control groups on the training problem reflected guessing in response to questioning. If this were so, scores would have been lower for attention than for information controls because they were questioned more often. It is probable that asking the child whether he knew the answer counteracted lapses in attention by reminding him that the purpose in pressing bulbs was not to see whether they would light up, but to find which pattern was on the board. Because control $\mathrm{S}_{\mathrm{s}}$ performed at no better than the pretest level on the transfer tests, it is clear that they had learned nothing from simply having paid closer attention on the training problem. On the other hand, since the performance of neither control group deteriorated significantly from the training level until the $18 \cdot \mathrm{h}$ transfer test, there was evidence of minimal but transient transfer from the control procedures.

The most important finding, however, was that an effect attributable to having been permitted only one press at a time was demonstrated not only on the training problem, but also on the test for transfer 2 days later. The speedier solutions of the children under constraint reflected the fact that they, with one exception, solved the problem following the first informative press. The fact that such solutions were rare in the attention control group indicates that the question following the press is rarely sufficient-at least not in children as young as 5 years-to trigger recognition, and then utilization, of information just encountered. Even when attention was drawn to information by making the enquiry only after informative presses, few children were able to capitalize on the hint and use the information to solve the problem. The training problem data have two implications. The highly efficient use of information typical of Ss under constraint is, in fact, the earmark of an information-seeking strategy which culminates in a hypothesis about which pattern is on the board. Moreover, the strategy itself is elicited because the child is forced to think in terms of a one-press solution prior to making each press.

The $S$ s in the constraint group showed evidence of immediate transfer in that they, unlike control Ss, solved the problem given immediately after training faster than the pretest problem. This transfer could not be attributed solely to their having been permitted only one press at a time on the training problem, since constraint Ss neither solved the immediate transfer problem significantly faster than the attention controls nor differed significantly from them in the number of solutions of the problem which suggested the use of strategy-i.e.. solutions following the first informative press. It should be noted, lowever, that the few such solutions that were produced by children who had just experienced constraint apparently demonstrated genuine learning of the appropitiate use of the information-seeking strategy elicited under constraint, since the three Ss who did achieve solution following the first informative press when tested for immediate transfer also did so when tested for transfer 2 days later.

The dichotomy in the data obtained for the constraint group on the $48 \cdot \mathrm{h}$ 
transfer test reflected the fact that 2 days after training, half the children in the group, like the control Ss, showed no evidence of transfer, whereas half essentially behaved as if still under constraint. The rapid solutions (one to four presses) of the six Ss who showed evidence of transfer were associated with the typical information-seeking strategy elicited under constraint, with its earmark of solution following the first informative press in four cases and a less efficient variation of it in two others. The variation in strategy, which was not seen in control Ss on either transfer problem, clearly indicated information selection on the part of the S. It consisted of following the first informative press, which happened to be of a bulb that did not light because it was part of the "incorrect" pattern, with a second informative press before giving the answer. Presumably, the second informative press was taken to confirm the first, since it was a press of an informative bulb that was part of the alternate and "correct" pattern. Why three of the six Ss who engaged in information selection on the 48 -h transfer test had not done so on the test for immediate transfer is not clear. Possibly these children were sufficiently flustered by the abrupt transition from the constraint procedure experienced on the training problem to the very different free condition under which the transfer problem was solved that they simply did not put their knowledge of the appropriate strategy into use.

Inspection of the training problem data for all members of the constraint group suggested that a certain minimum amount of experience was required in order for a child to internalize constraint. All three children who produced single-press solutions under constraint failed to show any evidence of information-seeking behavior on the 48-h transfer test. On the other hand, four of the five children who were the slowest to solve the training problem, in that they required four presses to find a bulb that would yield the necessary information, showed evidence of transfer 2 days later by their use of an information-selection strategy to solve the transfer problem.

In conclusion, Experiment 2 indicated the necessity of including an attention control group in research concerned with the salient characteristic of constraint. It also showed that constraint is an effective way to teach young children how to attack one kind of logical problem. To obtain maximum benefit from constraint training, however, the data suggest that problems should be sufficiently difficult that all children require several presses to achieve solution and thus experience constraint repeatedly.

\section{REFERENCES}

OLSON, D. R. On conceptual strategies. In J. S. Bruner, R. R. Olver, P. M. Greenfield et al (Eds.), Studies in cognitive growth. New York: Wiley, 1966. Pp. 135-153. 